\title{
Stimulus duration effects on secondary reinforcement'
}

MONA MORNINGSTAR, NANCY A. MYERS AND JEROME L. MYERS ${ }^{1}$

Delay of primary reinforcement in training and stimulus duration in extinction were manipulated with kindergarten children as $S s$ on a push-button task. Each $S$ was exposed to two different potential secondary reinforcers (PS's) (red and orange lights) for two different stimulus durations (10 sec. and 1 sec.) in training, and one PS duration combination (either red-1 sec., red-10 sec., orange-1 sec., or orange-10 sec.) in extinction. The PS duration in extinction could be the same or different from any $\mathrm{PS}^{r}$-duration combination experienced in training. Control groups received the same schedule of 1 and $10 \mathrm{sec}$. trials in training, but the PS was a white light for both durations. Ss responded at a higher rate with a 10-sec. stimulus following a response in extinction than with a 1-sec. stimulus. There were no significant differences between experimental and control groups. Results were interpreted in the light of magnitude of reinforcement, and the discrimination hypothesis.

The purpose of this experiment was to examine, with children as Ss, the effects of a delay of primary reinforcement in training, and stimulus duration in extinction, on the secondary reinforcing value of a stimulus. Although delay has been demonstrated to be an effective learning parameter in the child literature (Walters, 1964; Etzel \& Wright, 1964; Lipsitt \& Castaneda, 1958), experiments concerned with secondary reinforcement have focused on the effects of other major parameters of reinforcement, percentage and amount (Myers, 1958).

In the present study, the duration of the potential secondary reinforcer ( $\mathrm{PS}^{\mathrm{r}}$ ) was manipulated both in training and extinction. Each $\mathrm{S}$ was exposed to two different stimulus durations in training (10 sec. and 1 sec.), and one in extinction (10 sec. or 1 sec.). Two stimuli were used as $\mathrm{PS}^{\mathrm{r}}$ 's in training, one for each duration. Only one of the stimuli presented in training was used as the $\mathrm{PS}^{\mathrm{r}}$ for extinction. The $\mathrm{PS}^{\mathrm{r}}$-duration combination which followed a response in extinction could be the same or different from any $\mathrm{PS}^{\mathrm{r}}$-duration combination experienced in training. According to the discrimination hypothesis (Bitterman et al, 1953; Myers \& Myers, 1965), those groups with a novel $\mathrm{PS}^{\mathrm{r}}$-duration combination in extinction should respond at a lower rate than the groups with a combination they have already experienced.

Method

The Ss were 96 children attending kindergarten and nursery schools in Northampton, Massachusetts. The apparatus and general procedure have been described previously (Myers \& Myers, 1965).
Training for the experimental groups consisted of 80 trials; for 40 of these, a button press led to a light of 1 sec. duration (1), while for the other 40 trials, a button press led to a different color light of $10 \mathrm{sec}$. duration (10). The $1 \mathrm{sec}$. and $10 \mathrm{sec}$. lights were presented randomly, followed on $20 \%$ of the trials by a candy, the candy being equally distributed between the 1 and 10 sec. trials. The groups were counterbalanced with respect to the color light (red or orange) associated with a given duration. The control groups received the same schedule of 1 and $10 \mathrm{sec}$. trials, but the stimulus was always a white light during training.

During extinction, each $\mathrm{S}$ experienced a light whose color (red or orange) and duration (1 or $10 \mathrm{sec}$.) was the same after every button press. The groups differed with respect to two factors: (a) the color used in extinction might have been previously present for 10 sec., 1 sec., or not present (control) during training; (b) the color appeared for either $1 \mathrm{sec}$. or $10 \mathrm{sec}$. following each extinction response. The six groups are labeled $1-1,10-1, C-1,1-10,10-10$, and $C-10$, where the first designation refers to duration of the extinction color in training, the second to duration of the extinction color in extinction.

Throughout the training and extinction periods, $\mathrm{S}$ was allowed to respond at his own rate. Time to complete training was recorded. During the extinction period, $E$ recorded the number of button presses per minute until $S$ chose to stop, or until the end of $20 \mathrm{~min}$. at which time E terminated the session.

\section{Results and Discussion}

Because Ss were unable to respond again until the termination of the light stimulus, and since the $10 \mathrm{sec}$. stimulus eliminated responding for a much longer period, it became necessary to equate tine maximum number of possible responses per minute for the groups receiving $1 \mathrm{sec}$. and $10 \mathrm{sec}$. stimuli in extinction. Therefore, the number of responses for the $10 \mathrm{sec}$. group was multiplied by a factor of 10 . The average number of responses for each 4-min. block of extinction for each group is shown in Fig. 1. Ss responded at a higher rate with a $10 \mathrm{sec}$. stimulus following a response in extinction than with a 1 sec. stimulus $(p<.001)$.

The lack of differences as a function of training, between the experimental and control groups, indicates that the difference found as a function of stimulus duration during extinction, rather than any specific secondary reinforcement effect, may be a simple preference for a long rather than a short stimulus, as 


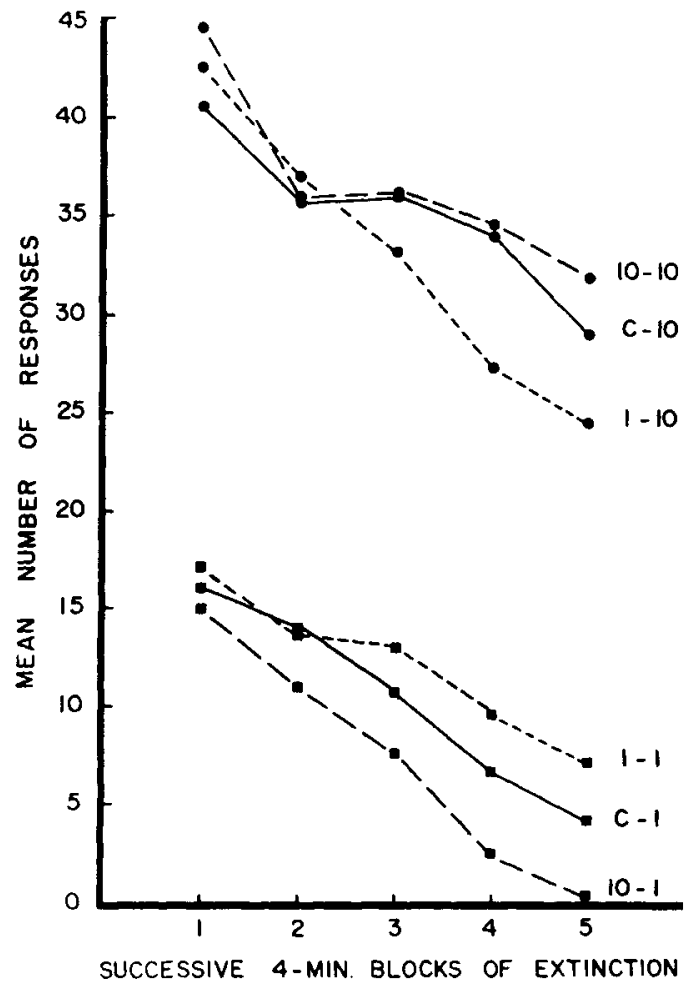

Fig. 1. Mean number of responses for successive four-minute blocks of extinction.

would be predicted by any magnitude of reinforcement theory (Pubols, 1960). It is also possible that the control groups, although trained with white lights, simply generalized secondary reinforcing characteris- tics to the colored light used in extinction. Further research into the phenomenon of generalization of secondary reinforcement should prove interesting.

The usual decrease in response rate over time blocks in extinction was also significant $(p<.001)$. Within each duration condition, the groups receiving the same light-duration compound in extinction as they experienced in training $(1-1,10-10)$ responded more than the groups in which this compound differed from training to extinction $(1-10,10-1)$. Although the interaction was not significant, this trend is in agreement with predictions of the discrimination hypothesis of extinction behavior.

\section{References}

Bitterman, M. E., Fedderson, W. E., \& Tyler, D. W. Secondary reinforcement and the discrimination hypothesis. Amer.J.Psychol. $1953,66,456-464$

Etzel, B. C., \& Wright, E. J. Effects of delayed reinforcement on response latency and acquisition learning under simultaneous and successive discrimination learning in children. $J$. exp. child Psychol., 1964, 1, 281-293.

Lipsitt, L. P., \& Castaneda, A. Effects of delayed reward on choice behavior and response speeds in children. $J$. comp. physiol. Psychol., 1958, 51, 65-67.

Myers, J. L. Secondary reinforcement: A review of recent experimentation. Psychol. Bull., 1958, 55, 284-301.

Myers, N. A., Myers, J. L. A test of a discrimination hypothesis of secondary reinforcement. J. exp. Psychol., 1965, 70, 98-102.

Pubols, B. Incentive magnitude, learning, and performance in animals. Psychol. Bull., 1960, 57, 89-115.

Walters, R. M. Delay of reinforcement gradients in children's learning. Psychon. Sci., 1964, 1, 307-308.

\section{Note}

1. This research was supported by funds from National Institutes of Health Grant HD-00898-06. The authors wish to thank Mr. William Barry, Superintendent of Schools, Northampton, Massachusetts, for his cooperation in providing $S s$ and facilities for this study. 